\title{
Imagery, Affect, and Decision Making
}

\author{
Paul Slovic,* Donald G. MacGregor, Ellen Peters
}

Decision Research

1201 Oak Street

Eugene, OR 97401 USA

(541) $485-2400$

March 11, 1998

*To whom all correspondence should be sent 


\begin{abstract}
Traditionally, the principal focus of research on judgment and decision making has been largely cognitive and rationalistic. More recently, however, decision-making researchers have acknowledged the role of noncognitive factors and have offered limited accounts of how affect and imagery influence processes associated with judgment and choice. The present paper extends this direction by offering evidence from three studies conducted in widely diverse contexts that support the view that the concepts of mental imagery and affect can provide a powerful framework for predicting both intended and actual behavior from relatively simple imageelicitation techniques. The implications of this evidence are discussed in terms of their significance for imagery and affect to act as organizing principles in theories of judgment and decision making.
\end{abstract}

Key words: Affect, decision making, judgment 


\section{Introduction}

Our objective in this paper is to present evidence in support of a theory of judgment and decision making based on the concept of mental imagery and affect. Imagery is broadly construed to include sights, sounds, smells, ideas, and words, to which positive and negative affect or feeling states have become attached through learning and experience. The notion that affect-laden imagery guides decisions appears in the writing of many behavioral theorists over the past century. To name just one, psychologist Hobart Mowrer summarized a vast body of research on human learning and motivation conducted during the first half of the $20^{\text {th }}$ century by concluding that behavior is determined by conditioned emotional responses to images, reflecting prospectivc gains and losses, that "guide and control behavior in a generally sensible, adaptive manner" (Mowrer, 1960, p. 30). Mowrer criticized theorists who postulated purely cognitive variables such as expectancies intervening between stimulus and response, reiterating the concern of Guthrie (1952) that we must be careful not to leave the organism at the choice point "Iost in thought." Mowrer's solution was to view expectancies more dynamically, as conditioned emotions such as hopes and fears, which serve as motivating states leading to action.

Although imagery, affect, and emotion have long played a key role in many behavioral theories, these concepts have rarely been recognized as important by students of human judgment and decision making. Perhaps befitting its rationalistic origins, the main focus of descriptive decision research has been cognitive. When principles of utility maximization failed to be descriptively accurate, Simon (1956) oriented the field toward problem solving and information-processing models based upon bounded rationality and concepts such as satisficing (as opposed to maximizing). The work of Tversky and Kahneman (1974) demonstrated how boundedly rational individuals employed heuristics such as availability, representativeness, and 
anchoring and adjustment to make judgments, and how they used simplified strategics such as "elimination by aspects" to make choices (Tvcrsky, 1972). Other investigators elaborated the cognitive strategies underlying judgment and choice through models of constructed preferences (Slovic, 1995; Payne, Bettman, \& Johnson, 1992), dominance structuring (Montgomery, 1983), and comparative advantages (Shafir, Osherson, \& Smith, 1989). In 1993, in an cntire volume of the journal Cognition dedicated to the topic of Reason-Based Choice, it was argued that "Decisions ... are often reached by focusing on reasons that justify the selection of one option over another" (Shafir, Simonson, \& Tversky, 1993, p. 34). Similarly, a recent state-of-the-art review was titled "Decision Making from a Cognitive Perspective" (Busemeyer, Hastie, \& Medin, 1995). In keeping with its title, it contained almost no references to the influence of affect and emotion on decisions,

Despite this cognitive emphasis, the importance of affcct ${ }^{\mathrm{I}}$ and emotion is increasingly acknowledged by decision researchers. A limited role for affect was acknowledged by Shafir et al. (1993) who conceded that "People's choices may occasionally stem from affective judgments that preclude a thorough evaluation of the options" (p. 32, italics added).

A strong early proponent of the importance of affect in decision making was Zajonc (1980), who argued that affective reactions to stimuli are often the very first reactions, occurring automatically and subsequently guiding information processing and judgment. According to Zajonc, all perceptions contain some affect. "We do not just see 'a house:' We see 'a handsome

\footnotetext{
'Affect may be viewed as a feeling state that people experience, such as happiness or sadness. It may also be viewed as a quality (e.g., goodness or badness) associated with a stimulus. These two conceptions tend to be related. This paper will be concerned with both of these aspects of affect.
} 
house," "an ugly house," or "a pretentious house"" (p. 154). He later adds, "We sometimes delude ourselves that we proceed in a rational manner and weigh all the pros and cons of the various alternatives. But this is probably seldom the actual case. Quite often "I decided in favor of $\mathrm{X}$ " is no more than 'I liked X ...' We buy the cars we 'like," choose the jobs and houses we find 'attractive, and then justify these choices by various reasons ..." (p. 155).

More recently, a comprehensive and dramatic theoretical account of the role of affect and emotion in decision making has been presented by the neurologist, Antonio Damasio (1994). Damasio"s view is remarkably similar to Mowrer's. In seeking to determine "what in the brain allows humans to behave rationally," Damasio argues that thought is made largely from images, broadly construed to include perceptual and symbolic representations. A lifetime of learning leads these images to become "marked" by positive and negative feelings linked directly or indirectly to somatic or bodily states. When a negative somatic marker is linked to an image of a future outcome, it sounds an alarm. When a positive marker is associated with the outcome image, it becomes a beacon of incentive. Damasio hypothesized that somatic markers increase the accuracy and efficiency of the decision process and their absence, observed in people with certain types of brain damage, degrades decision performance.

Other important work on affect and decision making has been done by Epstein (1994), Isen (1993), Johnson and Trersky (1983), Janis and Mann (1977), Kahneman and Snell (1990), Mellers, Schwartz, Ho, and Ritov (1996), Loewenstein (1996), Rozin, Haidt, and McCauley (1993), and Wilson et al. (1993).

In the present paper, we provide evidence for the Mowrer-Damasio theories by examining the relationships between imagery, affect, and decisions in a variety of contexts. We operationalize imagery through word associations and we operationalize affect by having 
individuals rate the associations they produce on a scale from very bad to verv good. We shall demonstratc that these quick, intuitive, affectively-Iaden associations are strongly predictive of a diverse range of judgments, decisions, and behaviors.

\section{Study 1: 1mages, Affect, and Vacation/Migration Decisions}

Our program of research on the relationship between images, affect, and decision making began more than a decade ago, as part of an effort to answer the following applied question: "What is the potential for a high-level nuclear waste repository at Yucca Mountain, Nevada, to have adverse economic effects on the city of Las Vegas, and the State of Nevada, during a 40- to 60 -year period of constructing and filling the repository?"

The economic impacts of concern to us included reduction in short-term visits to the city and state by vacationers or conventioneers, effects on long-term residents (moving out of the region, reduced immigration of retirees), and reduced ability to attract new businesses. Assessment of these impacts is obviously important to citizens and officials of Nevada who need to know what economic consequences to expect if Yucca Mountain is developed as the nation's primary repository.

Empirical research on this topic faces some major obstacles, however. For example, one obstacle to survey research is the fact that people may not really know how the repository will affect their future dccisions or the decisions of their successors. As a result, asking people to project the repository's impacts on personal plans to be made many years hence, may, in effect, be asking them to "tell more than they can know" (Nisbett \& Wilson, 1977).

ln order to avoid the problems of relying upon untrustworthy answers to hypothetical questions, our studies employed an indirect strategy, based on the notion of environmental imagery (Slovic et al., 1991). Our studies were designed to demonstrate the concept of 
environmental imagery and show how it can be measured, to assess the relation between imagery and choice behavior, and to describe economic impacts that might occur as a result of altered images and choices.

Specifically, our research was designed to test the following three propositions:

1. Images associated with environments have diverse positive and negative affeetive meanings that influence preferences (e.g., in this case, preferences for sites in which to vacation, retire, find a job, or start a new business).

2. A nuelear waste repository evokes a wide variety of strongly negative images, consistent with extreme pereeptions of risk and stigmatization.

3. The repository at Yucca Mountain and the negative images it evokes will, over time, become inereasingly salient in the images of Nevada and of Las Vegas.

If these three propositions are true, it seems quite plausible that, as the imagery of Las Vegas and of Nevada becomes increasingly associated with the repository, the attractiveness of these places to tourists, job seekers, retirees, and business developers will decrease and their choices of Las Vegas and Nevada within sets of competing sites will decrease.

Support for these three propositions, therefore, would demonstrate the mechanism whereby the repository could produce adverse affects upon tourism, migration, and business devclopment in Nevada and this demonstration would occur without having to ask people to make questionable introspective judgments about their future behaviors.

Survey Design. In order to test the propositions described above, we conducted three surveys of imagery and preference. Studies 1 and 2 surveyed representative samples of residents in Phoenix, Arizona. Study 1 elicited images for four cities and asked people to indicate their preferences among these cities as places to vacation, take a new job, or retire. Study 2 did the 
same for four states. Study 3 surveyed a national sample of business executives, asking for their images of each of four cities and their preferences among these cities as places to open a new business or expand an existing business. All three surveys were conducted by telephone. Each survey had a sample size of about 400 persons.

The survey questions in Studies 1 and 2 were nearly identical. The cities questionnaire asked respondents to provide images for San Diego, Las Vegas, Denver, and Los Angeles. The states questionnaire elicited imagery for California, Nevada, Colorado, and New Mexico. These cities and states, in addition to Las Vegas and Nevada, were chosen for the study because they are important vacation destinations for residents of Phoenix.

The images were elicited using a version of the method of continued associations (Szalay \& Deese, 1978), adapted for use in a telephone interview. Image elicitation was always the first task in the survey. In the cities survey, the elicitation interview proceeded as follows:

My first question involves word association. For example, when I mention the word "baseball," you might think of the World Series, Reggie Jackson, summertime, or even hot dogs. Today, I am interested in the first SIX thoughts or images that come to mind when you hear the name of a PLACE. Think about [CITY] for a minute. When you think about [CITY], what is the first thought or image that comes to mind? What is the next thought or imagc you have when I say [CITY]? Your next thought or image? What is another thought or image you have about [CITY]?

This continued until six associations were produced or the respondent drew a blank. Then the procedure was repeated for the next city. The order of the cities was rotated across respondents. The procedure was identical for the states and business-location surveys. 
Following the elicitation of images, respondents were asked to rate each image they gave on a scale of very positive $(+2)$, somewhat positive $(+1)$, neutral $(0)$, somewhat negative $(-1)$, or very negative $(-2)$.

Respondents in Studies 1 and 2 were then asked to rank the cities/states according to their preference for a vacation site (long weekend vacation for cities; week or longer vacation for states). Subsequent questions asked for a preferenee ranking among these cities or states as retirement sites or places to move to (assuming equally attractive job offers in each place), much in the same manner as vacation preferences were elieited. Next, up to six images were clicited to the stimulus "underground nuclear waste storage facility" and the stimulus "nuelear test site."

The survey of corporate decision makers (Study 3) first elicited images for each of four cities-Phoenix, Las Vegas, Denver, and Albuquerque-and then asked the respondents to evaluate these images on the -2 to +2 rating scale, as in the other surveys. Respondents were then asked to rank these cities in order of preference as a location for opening or expanding a business, assuming that market conditions and cost conditions were about equal in each location.

Results. The results of all three studies were consistent with one another and with the hypothesis that preferences are guided by affect-laden imagery. To prediet preferences among cities from images, we developed a scoring rule, the summation model, whieh simply sums the ratings for all the images a respondent produced for each city. A person's preferences among cities were hypothesized to be predictable from these sums. An example, illustrating the application of the summation model to the data of one respondent, is given in Table 1. For this respondent, the rank order of summation scores exactly matched the preference order for vacation sites.

Insert Table 1 about here 
When ranks generated by the summation model wcre compared to the actual ranks generated by the respondents when they stated their preferences, the model did quite well, correctly predicting $55 \%$ of the number-one-ranked vacation cities and $56 \%$ of the fourth-ranked cities, with somewhat less accuracy in predicting intermediate ranks (if the model lacked predictive validity, we would expect a $25 \%$ hit rate by chance). The exact rank order of four cities generated by the summation model matched the exact rank order of the respondent $26.4 \%$ of the time (perfect matching of ranks would be expccted by chance only $4.2 \%$ of the time).

Figures 1 and 2 illustrate the performance of the summation model across all pairs of cities and all pairs of states, based upon the predictions of a logistic regression model. The data show that imagery and preference for vacation cities and states are strongly related. If city $B$ has a more positive set of images than city A (as indicated by simply summing the affect ratings across images produced for each city), then city $B$ is more likely to be preferred as a vacation site. The greater the difference between image scores for the two cities or states, the more likely it is that the place with the more positive images will be preferred.

Insert Figures 1 and 2 about here

The summation model was applied in similar fashion to the prediction of job preferences and retirement preferences for the cities survey. The hit rates were similar to those reported earlier for vacation preferences and the functional relationships relating job and retirement preferences to image scores were almost identical to the relationship shown in Figure 1.

Similar analyses showed that the summation model was about as accurate in predicting job, vacation, and retiremcnt preferences among states as it was for predicting preferences among cities. The model was equally accurate in predicting preferrcd locations for siting a new business as expressed by the sample of corporate decision makers. 
In summary, three separate surveys totaling more than 1,200 respondents demonstrated that a simple summation model applied to sets of images did a good job of predicting expressed preferences for cities and states in which to vacation, take a new job, retire, or site a business. The slopes of the best-fitting lines relating preferenccs among pairs of cities/states to differences in image values were quite stcep, indicating that a change in the affective quality of one or two images could imply a substantial shift in preference probability.

Imagery and actual vacation behavior. The previous analyses demonstrated that images could predict expressed prefcrences for vacation sites. Can image scores also predict actual vacation trips? To address this question we attempted to resurvey the same 802 respondents from our 1988 Phoenix survcys some $16-18$ months later (October - December 1989). We were successful in re-interviewing about 130 persons in each of the two samples (cities survey and states survey) studied carlicr. Again, we elicited six word associations to each of the same four cities or four states and asked for positive/negative ratings of each image produced. In addition, we asked the respondents to indicate in which of these cities (or states) they had vacationed since the previous survey was conducted.

The overall affective score, based upon the sum of the ratings, was moderatcly reliable over this 18 -month period. The test/retest correlation was .52 for cities and .42 for states,

The predictive capability of the word-association image scores was tested by means of logistic regression analysis using a person's 1988 image score for a state or city to estimate the probability that that person would vacation in a place during the subsequent $16-18$ months (until the date of the repcat survey). The cstimated probabilities for both citics and states are presented in Figures 3 and 4. These data show that the affective qualities of a person's images of 
a place were clearly related to the probability that the person would subsequently vacation there, with the relationship being stronger for states than for cities.

lnsert Figures 3 and 4 about here

Discussion. The results of this study supported the three propositions that the research aimed to test: Images of cities and states, derived from a word-association technique, exhibited positive and negative affective meanings that were highly predictive of preferences for vacation sites, job and retirement locations, and business sites (Proposition 1).

Additional analyses, which shall not be described here, showed that nuclear images were affectively quite negative and persons exhibiting a nuclear image in their associations to Nevada expressed much reduced preferences for that state as a vacation site (Propositions 2 and 3 ).

Although this research was unable to provide a definitive answer to the question about future repository impacts, it did demonstrate that increased association of nuclear imagery with Las Vegas and Nevada would likely decrease the attractiveness of those places.

\section{Study 2. Imagery, Affect, and Financial Judgments}

We next applied the word-association technique to a study of judgments about initial public offerings of common stocks (MacGregor, Slovic, Dreman, \& Berry, 1997). We hypothesized that a stock offering that has a highly positive affective evaluation is likely to be seen as good in terms of a number of other specific attributes, such as the quality of its management or its prospects for long-term financial success. However, the basis for the affective evaluation may not be related to management quality or financial soundness, but rather to the association of the company with exciting or glamorous qualities of its business sector. Indecd, the image of the company may play a potent role in its affective evaluation, thereby resulting in a discounting of other information that should be incorporated into a judgment of its overall 
quality or worth. For new companies, such as Initial Public Offerings (IPOs) that have a very limited track record, the image of the company and its affective evaluation may be a major basis on which potential investors make investment deeisions.

Method. We tested the hypothesis that affect can play a significant role in finaneial judgments by studying the responses of a group of 57 university-age business students enrolled in an upper division investment banking course at James Madison University in Harrisonburg, VA. The students were asked to make various judgments, ineluding images and image ratings, of 20 different industry groups, characterized by name only (e.g., computer software, pharmaceuticals, railroads, managed health eare) selected from 132 industry groups comprising offerings on the NYSE. Altogether 40 different industry groups were studied, divided into two sets of 20. Approximately half of the subjects reeeived one set, and half the other. The industry groups were selected on the basis of average price returns of stocks within each group for the period January 1, 1994 to December 9, 1994; half of the industry groups were partieularly high performers (e.g., $5 \%$ to $40 \%$ positive return), and the other half were particularly low performers (e.g., $5 \%$ to $40 \%$ negative return). Therefore, of the 20 industry groups assessed by each subject, 10 were high performers and 10 were low performers based on the past year's price returns. The study was condueted in May of 1995, providing an opportunity for subjeets to judge industry group performance for the previous year (i.e., 1994), as well as expected performance for the current year (i.e., 1995).

The task was divided into two parts. In the first part, subjects were given a booklet with one industry group appearing at the top of each page (e.g., Photographic Produets). Below the name of each industry group, space was provided to write the first three "thoughts or images" 
that came to mind. After providing images for all 20 industry groups, subjects rated each image on a five-point scale ranging from highly negative $(-2)$ to highly positive $(+2)$.

In the second part of the task, subjects received another booklet that contained the same 20 industry groups seen previously, with one per page as before. For each industry group, subjects made affective ratings on the semantic differential dimensions shown in Table 2 below.

Insert Table 2 here

In addition, subjects indicated for each group their familiarity with companies in the group, and whether or not a significant company in the group came to mind. Finally, subjects judged each industry group on three performance criteria: (1) returns relative to the market of the group in the past year (Judge 1994), (2) predicted returns relative to the market for the coming year (Judge 1995), and (3) likelihood that they would buy an IPO of a company belonging to the group (BUY IPO). Table 3 contains the complete wording of each scale along with its response format.

Insert Table 3 here

Results. Overall, the three judgment measures were highly correlated, as shown in Table 4. Likelihood of IPO purchase was most highly correlated with judged performance in the coming year (i.e., 1995).

However, respondents' judgments of financial performance were, in general, poorly correlated with the actual market performance of the 40 industry groups studied. ${ }^{2}$ Table 4

\footnotetext{
${ }^{2}$ The performance of an industry group was measured in three ways: the simple average, the weighted average (computed by weighting the returns of individual companies by their number of shares), and the median return.
} 
indicates that only for a weighted average of returns by industry group did the correlation with judged performance approach a modest level. The relatively high level of internal consistency apparent in the performance judgments of these respondents did not translate into a strong ability to predict actual market returns.

Insert Table 4 here

Table 5 shows the intercorrelations of the six semantic differential scales used to assess affect, as well as their correlation with average image ratings for each industry group (Imagery) ${ }^{3}$ and a dichotomous variable indicating whether or not respondents could think of a company belonging to each of the industry groups (Think Co.).

Insert Table 5 here

The table reveals a mixed pattern of intercorrelations. The BADGOOD scale correlated moderately well with EXCITING, VALUABLE, and STRONG, but relatively poorly with ACTIVE and RISKY. Indeed, the RISKY scale tended to have quite low correlations with the remaining five semantic differential scales, suggesting that it is a somewhat distinct measure. Correlations of the six semantic differential scales with image ratings varied greatly, from a high of .83 (with BADGOOD) to a low of .15 (with ACTIVE). Imagery correlated quite poorly with whether or not a significant company came to mind, suggesting that imagery is not simply a result of the association of an industry group with a particular company. Indeed, memorable association of a company with industry groups correlated rather marginally with all of the affective variables, again suggesting that affect and imagery go beyond mere salience in memory.

\footnotetext{
${ }^{3}$ We used average ratings rather than a summation score because not all respondents gave three images.
} 
Table 6 shows the results of three stepwise multiple regressions, predicting each of the three judgmental scales from the set of image and affect scales. In all three cases, the imagery variable was forced into the multiple regression first, and the remaining variables were allowed to enter according to the usual stepwise rule. The simple correlations of image ratings with the three judgmental variables werc modcrately high.

\section{Insert Table 6 here}

All three judgmental variables were highly predictable from a combination of imagery and affective ratings. The multiple $\mathrm{R}^{2}$ values ranged from a low of .68 for judged performance in 1994, to a high of 80 for BUY IPO. Once again, the results revealed a high level of internal consistency in subjects' judgmental framework, with judgments of financial performance of industry groups strongly related to a combination of the strength of imagery associated with the various industry groups studied as wcll as affective evaluations based on semantic differential ratings.

Discussion. Respondents' different judgment ratings in this study exhibited a surprisingly high degree of internal coherence. Imagery scores and affective ratings of industry groups correlated nicely with predictions and expectations of financial performance, including willingness to purchase shares of an initial public offering for a stated industry group. Imagery and affect appeared to have a very powerful influence upon judgments of the quality of financial stimuli under conditions where financial fundamentals about a particular company or firm is absent.

It does, of course, remain to be demonstrated how the power of imagery and affect are influenced as the information environment for judging financial performance becomes richer. Though it may be tempting to predict that solid, concrete information about a financial offering 
will significantly dilute the role that affect and imagery play in judgments of financial performance, alternative predictions can be made as well. For example, as the sheer quantity of information becomcs large, human judgment tends to become more rcliant on simplifying rules or heuristics that either take advantage of only partial information or process information in incomplete ways. One can well imagine circumstances in which the evaluation of a financial prospect takes place in an environment that is characterized by both highly dense and conflicting information. In these circumstances, the complexity of the task may drive the respondent to weigh affective cues more heavily than technical indicators.

\section{Study 3. Adolescents' Images of Health-Threatening and Health-Enhancing Behaviors}

This study, conducted by Benthin et al. (1995), used the word association methodology to explore adolescents' conceptual images related to a variety of health-threatening and healthpromoting behaviors. Based upon the findings reported in Study 1 above, images associated with health-related behaviors were hypothesized to be linked with positive and negative affective evaluations and these evaluations were expected to predict participation in those behaviors.

Method. Participants were recruited through a high school (grades 9 through 12) located in a small coastal town in Oregon. The sample consisted of all the students who attended school on a regular school day $(n=411)$. The age range was between 14 and 20 years. Fifty-one percent $(\underline{n}=209)$ of the sample were female, $47 \%(\underline{n}=195)$ were male, and $2 \%$ of the sample $(\underline{n}=7)$ did not report gender.

Information about participation in health-threatening and health enhancing activities was obtained for each subject by asking, "How many times have you done this activity during the past 6 months (never, occasionally, frequently)?" Subjects were then given the Teen Imagery Survey with the following introductory instructions: 
We all have images and ideas about things. Often when people hear about certain behaviors, they develop certain images in their mind about the meaning of these behaviors. We are interested in the meaning of certain behaviors to people your age.

In answering these questions, please make your judgments on the basis of what these behaviors mean to you. Work at a fairly high speed through this test. Do not worry or puzzle over your answers. It is your first impressions, your immediate thoughts that we want. On the other hand, please do not be careless, because we want your true impressions.

It is important that in answering these questions, you always focus on the specific behavior that we ask about. For example, if we ask you about thoughts that come to your mind when you think about playing sports, it is important that you think about playing sports each time you write down a new thought about playing sports.

Subjects were asked to associate to each of eight behaviors. For example, for the stimulus behavior drinking beer, the instructions were as follows: "Think for a moment about drinking beer. We are interested in the first FIVE thoughts that come to mind when you think about drinking beer."

The eight behaviors included five considered to be health-threatening and three behaviors considered to be health-enhancing. The health-threatening behaviors were drinking beer, drinking liquor (e.g., vodka, mixed drinks), smoking cigarettes, smoking marijuana, and having sexual intercourse. The three health-enhancing behaviors were exercising, wearing a seat belt, and using a condom during sexual intercourse. These behaviors were selected on the basis of prevalence and importance from a health standpoint.

Following the elicitation of image associations for each particular behavior, the subject was asked to provide an affective image rating on a five-point rating scale. 
Results. The 411 respondents provided a total of 15,650 word-association images to the eight stimulus behaviors. The greatest number of word associations $(\underline{n}=1,895)$ was given for the stimulus drinking beer, and the fewest number $(\underline{n}=1,562)$ was given for the stimulus using a condom. The content of these associations was examined for each stimulus behavior, and the researchers developed a classification scheme to assign the associations to various content categories. The category assignments were made by the first author of the study and checked by two of the other authors.

This content analysis resulted in five general or superordinate categories for each stimulus behavior: positive concepts or positive descriptions of the behavior (e.g., nice, awesome), positive outcomes associated with the behavior (e.g., fun, social facilitation), negative concepts or negative descriptions of the behavior (e.g., dirty, ugly), negative outeomes associated with the behavior (e.g., accident, disease), and miscellaneous associations (e.g., references to family members, friends; see Table 7). Positivity and negativity were determined by the judges who did the content analysis. A reliability check was performed by having a second coder independently categorize a randomly selected set of 40 associations for each of the eight behaviors (about $20 \%$ of the total sample of associations). The second coder agreed with the first coder's assignment of superordinate categories in $85 \%$ of the cases. There were almost no instances of disagreement as to whether an association was positive or negative. Agreement on the distinction between a concept and an outcome was $93 \%$ for positive associations and $91 \%$ for negative associations.

Insert Table 7 about here

All superordinate categories contained subordinate categories. In all, there were 265 distinct subordinate categories across all eight stimulus behaviors. Table 8 presents the category 
structure for two activities, drinking beer and having sexual intercourse. Many of the subordinate categories contained multiple associations, evaluated to have similar meanings. For example, the category intimacy/affiliation, within the superordinate category positive outcomes for having sex, included terms such as intimacy, sharing, togetherness, and closeness.

Insert Table 8 about here

About one-half of the respondents said that they participated occasionally or frequently in drinking beer, drinking liquor, and sexual intercourse; participation was lower for smoking cigarettes and marijuana. Each of the health-enhancing behaviors was engaged in by more than $75 \%$ of the respondents.

Do those who participate in a particular activity produce different kinds of associations to that activity than do nonparticipants? Figure 4 addresses this question by comparing the associations of persons who said they never engaged in the various behaviors with the associations of those who had frequently taken part in these activities. It is clear that, for frequent participants, a much higher percentage of associations took the form of positive outcomes, as compared to nonparticipants. For example, $41.4 \%$ of the images given by adolescents who frequently drank beer were categorized as positive outcomes. In comparison, only $12.9 \%$ of the images given by non-beer drinkers were categorized as positive outcomes. Positive concepts did not differ as much between participants and nonparticipants, except for condom use (much higher positive concept percentage for users). Both negative outcomes and negative concepts formed a much ligher percentage of the image sets for nonparticipants than for participants.

Insert Figure 4 about here

In addition to examining the content categories, we also analyzed the relationship between the affective ratings of images and participation in health-related behaviors. These 
affect ratings were assigned by the respondents to each of their associations, and they are distinct from the assignment of the associations to positive and negative categories by the investigators. These ratings sometimes differed from the investigators' assignments. For cxample, an association such as "dangerous" may be rated positively by some respondents and negatively by others. In addition, the ratings lend themselves nicely to quantitative analysis, as shown below. Table 9 presents the results of regression analyses in which positive and negative image scores were used to predict frequency of participation (coded 0,1 , and 2 for never, occasionally, and frequent) for each of the eight behaviors. The positive (negative) image score is calculated for each respondent by summing all of the positive (negative) ratings given by that person. Positive ratings were stronger than negative ratings for predicting participation in drinking liquor, smoking marijuana, having sexual intercourse, and exercising; negative ratings were stronger predictors for cigarette smoking and seat-belt use; negative and positive ratings were about equally important in predicting beer drinking and condom usc. Overall predictability, as indicated by $\mathrm{R}^{2}$, was highest for drinking liquor, drinking beer, and smoking marijuana and was lowest for seat-belt use (which had a very skewed distribution for participation).

Insert Table 9 about here

To gain additional perspective on the association between imagery and behavior, a second multiple regression analysis was performed to predict participation in each behavior (participation was again coded 0,1 , or 2 ). In this analysis, inagery was represented by the average rating given to the associations a person produced to a particular behavioral stimulus. Age and gender were also entered into the regression equation whenever they were statistically significant. The average image rating was always a highly significant predictor. The resulting $\mathrm{R}^{2}$ values were similar to those in Table 9. 
The regression equations resulting from this analysis were used to generate a predicted behavioral participation index. The distribution of scores on this index was dichotomized at a point that maximized the combined number of correct predictions for never participating and frequently participating persons. The results are shown in Table 10 for three behaviors: drinking beer, sexual intercourse, and condom use. Entries in the cells of the table are frequencies. The column headings differentiate those who fall below the cutting score (labeled "no" for predicted nonparticipant) and those above the cutting score (labelcd "yes" for predicted participant).

1nsert Table 10 about here

Table 10 indicates the degree of association between the predictions based on the regression equations and the self-reported frequencies of behavior. It is clear that there is quite a distinct separation between never participating and frequently participating persons. Among those who never participated in a behavior, some $77-91 \%$ had index scores below the cutting score. For example, $166 / 182$ or $91.2 \%$ of those who said they had not had sexual intercourse were below the cutting score. Among those who frequently participated in the behaviors, between $42 \%$ (sexual intercourse) and $82 \%$ (drinking beer) were categorized as participants. Adopting a lower cutting score for sexual intercourse would correctly classify $96 \%$ of those who reported frequent sexual intercourse and include $84 \%$ of those who reported occasional sexual intercourse, at the cost, howevcr, of including in the predicted "yes" category $60 \%$ of those who reported no sexual intercourse.

Most of the predictability in these data came from the average image rating score. Deleting age and gender from the equations made only a small difference in the numbers. The point of this exercise was not to validate a prediction equation; we used no holdout sample for cross-validation. Moreover, the sample of young adults in this study cannot be 
considered representative of other populations. Rather, the point was to illustrate the rather striking degree of association between the affective quality of five words or phrases, quickly written on a page, and self-reported participation in three important health-related behaviors.

The finding that health-threatening behaviors were associated with specific positive outcomes for adolescents engaging in these behaviors has implications for programs designed to deter adolescents from engaging in risk behavior. Such programs should acknowledge that risk behavior fulfills important functions for adolescents and, therefore, offer less hazardous means to meet adolescents' needs.

Adolescents' positive affect toward health-threatening behaviors also carries important implieations for educational programs. For example, Ross et al. (1975) demonstrated that affect often persists even after complete invalidation of its original cognitive basis. Consequently, educational programs need to determine how to address affective as well as cognitive components in adolescents' behaviors.

Finally, where specific images and feelings are linked to participation in health-related behaviors, advertising and other messages can be evaluated to see whether they change imagery in a desirable or undesirable manner. For example, for years cigarette companies have said that their ads are not designed to make smoking more attractive to young people. The imagery analysis presented here provides a method for testing the impact of such advertising. 


\section{General Diseussion}

Billions of dollars are spent every year by companies and politicians to improve their images or the images of their products, based upon the assumption that imagery will influence decisions made by consumers and voters. The results of the three studies described above provide an empirical confirmation of this assumption. The affective quality of people's images was found to be strongly related to attitudes, preferences, and behaviors across a diverse set of problem contexts.

Although the advertising model of imagery led us to initiate work in this area, we were surprised at the degree to which 3-6 associations, provided quickly, tapped content and affect that was so indicative of a person's deeper attitudes, values, and preferences. We were also surprised that the sets of images provided to a stimulus city or state by the same person, 18 months later, would have such similar affective values, as indicated by test/retest reliabilities of .42 to .52 . While these reliabilities are not high by usual psychometric standards, they seem quite good given the unstructured and brief nature of this task.

The fact that image scores predict attitudes and preferences well despite their modest reliability suggests that increasing reliability by eliciting more images or using a different technique should lead to even better predictions. Evidence in support of this is provided by Peters (1997) who found that rating a stimulus (e.g., Las Vegas) on simple good/bad and like/dislike scales produced affective evaluations that were more reliable than scores based on ratings of word associations. The simplc rating scales were also more predietive of intended behaviors toward the stimulus object (e.g., "Do you plan to visit Las Vegas?"). Simple good/bad ratings of stimuli sueh as "chemicals" or "pesticides" were found by Slovic (1997) to be significantly correlated with toxicologists" judgments of technical matters such as the degree to which one could have confidence that animal studies can predict a chemical's effects on human healtl. 
We view the present studies as exploratory in nature. More work needs to be done to determine the optimal way to integrate affect across multiple images. We have used additive and simple averaging models but we have not employed designs capable of distinguishing these models (see, e.g.: Anderson, 198 I, for examples of how to do this). Research needs to be done to determine whether the first associations a person produces are consistently more predictive than later associations (Peters \& Slovic, 1996). The association technique, combined with ratings of the images on affective scales, offers a wide range of possibilities for quantitative empirical studies of affect and decision making.

Additional research needs to be done to understand the content of images. Benthin et al. found that many images could be classified as "outcome expectancics" (e.g., "getting sick"), thus providing a link with a large literature on expectancy theories of adolescent health-risk behaviors (Goldman, Brown, Christiansen, \& Smith, 1991; Brown, Christiansen, Goldman, 1987). Some associations seem to represent brief reasons for making a decision or expressing a preference such as "skiing" for Denver or "smog" for Los Angeles. Other responses are purely affective such as "beautiful place" or "horrible". The mix of affective and rational or analytic content is compatible with the notions of Damasio and others regarding the interconnectedness of affect and reason.

Though work along these lines is far from complete, the results of the studies presented in this paper make a compelling case for the fundamental organizing properties of affect and imagery and their importance in providing a psychologically coherent framework for understanding and predicting events in our world. We are struck by the similarity between the functional role of affect and imagery and a similar functionality provided by the mental models people use in reasoning about complex phenomena (e.g., Craik, 1943; Gentner \& Stevens, 1983; Johnson-Laird, 1983). Indeed, we speculate that affect and imagery are key mechanisms by 
which new information and experience are integrated with what we already know and believe to maintain a coherent impression of "reality." Like mental models that do not depend on their accuracy for their usefulness, the impressionistic framework offered by affect and imagery derives its utility from an ability to provide psychological meaning and, as we have seen in some of the studies presented in this paper, a predictive rationale for behavior. As research along these lines progresses, we anticipate further demonstrating that the psychological processes associated with decision making (e.g, preference ordering) directly invoke imagery and its related affective evaluation as a basis for judgment, choice, and behavior.

\section{Acknowledgement}

This research was supported in part by Grant Nos. SBR-9422754 and SBR-9709307 from the National Science Foundation. Additional support was provided by The David Dreman Foundation and Heartland Advisors, Inc. The authors would also like to thank Janet Douglas and Leisha Mullican for their fine job of manuscript preparation. 


\section{References}

Anderson, N. H. (1981). Foundations of information integration theory. New York:

Academic.

Benthin, A., Slovic, P., Moran, P., Severson, H., Mertz, C. K., \& Gerrard, M. (1995). Adolescent health-threatening and health-enhancing behaviors: A study of word association and imagery. Journal of Adolescent Health, 17, 143-152.

Brown, S., Christiansen, B., \& Goldman, M. (1987). The alcohol expectancy questionnaire: An instrument for the assessment of adolescent and adult alcohol expectancies. Journal of Studies on Alcohol, 48, 483-491.

Busemeyer, J., Hastie, R., \& Medin, D. L. (Eds.). (1995). Decision making from a cognitive perspective. San Diego: Academic.

Craik, K. (1943). The nature of explanation. New York: Cambridge University Press.

Damasio, A. R. (1994). Descartes' error: Emotion. reason, and the human brain. New York: Avon.

Epstein, S. (1994). Integration of the cognitive and psychodynamic unconscious. American Psychologist, 49, 709-724.

Gentner, D., \& Stevens, A. L. (1983). Mental models. Hillsdale, NJ: Erlbaum.

Goldman, M., Brown, S., Christiansen, B., \& Smith, G. (1991). Alcoholism and memory: Broadening the scope of alcohol-expectancy research. Psychological Bulletin, $110_{y}$ 137-146.

Guthrie, E. R. (1952). The psychology of learning (Rev. ed.). New York: Harper \& Bros. Isen, A. M. (1993). Positive affect and decision making. In M. Lewis \& J. M. Haviland (Eds.), Handbook of emotions (pp. 261-277). New York: The Guilford Press.

Janis, l. L., \& Mann, L. (1977). Decision making. New York: The Free Press. 
Johnson, E. J., \& Tversky, A. (1983). Affect, generalization, and the perception of risk. Journal of Personality and Social Psychology, 45, 20-31.

Johnson-Laird, P. N. (1983). Mental models. Cambridge, MA: Harvard University Press.

Kahneman, D., \& Snell, J. (1990). Predicting utility. In R. M. Hogarth (Ed.), Insights in decision making (pp. 295-310). Chicago: University of Chicago.

Loewenstein, G. (1996). Out of control: Visceral influences on behavior. Organizational Behavior and Human Decision Processes, 65, 272-292.

MacGregor, D. G., Slovic, P., Dreman, D., \& Berry, M. (1997). Imagery, affect, and financial judgment. Report No. 97-11. Eugene, OR: Decision Research.

Mellers, B. A., Schwartz, A., Ho, K., \& Ritov, I. (1996). Flation and disappointment: Emotional responses to risky options. Unpublished manuscript, Ohio State University. Montgomery, H. (1983). Decision rules and the search for a dominance structure: Towards a process model of decision making. In P. Humphreys, O. Svenson \& A. Vari (Eds.), Analysing and aiding decision processes (pp, 343-369). Amsterdam: North-Holland.

Mowrer, O. H. (1960). Learning theory and behavior. New York: John Wiley \& Sons, Inc.

Nisbett, R. E., \& Wilson, T. D. (1977). The halo effect: Evidence for unconscious alteration of judgments. Journal of Personality and Social Psychology, 35, 250-256.

Payne, J. W., Bettman, J. R., \& Johnson, E. J. (1992). Behavioral decision research: A constructive processing perspective. Annual Review of Psychology, 43, 87-131.

Peters, E. (1997). Affect, images, and preferences: A methodological review. Eugene: University of Oregon, Department of Psychology. 
Peters, E., \& Slovic, P. (1996). The role of affect and worldviews as orienting dispositions in the perception and acceptance of nuclear power. Journal of Applied Social Psychology, 26, 1427-1453.

Ross, L., Lepper, M., \& Hubbard, M. (1975). Perseverance in self-perception and social perception: Biased attributional processes in the debriefing paradigm. Journal of Personality and Social Psychology, 32, 880-892.

Rozin, P., Haidt, J., \& McCauley, C. R. (1993). Disgust. In M. Lewis \& J. M. Haviland (Eds.), Handbook of emotions (pp. 575-594). New York: Guilford.

Shafir, E., Osherson, D., \& Smith, E. (1989). An advantage model of choice. Journal of Behavioral Decision Making, 2, 1-23.

Shafir, E., Simonson, I., \& Tversky, A. (1993). Reason-based choice. Cognition, 49. $11-36$

Simon, H. (1956). Rational choice and the structurc of the environment. Psychological Review, 63, 129-138.

Slovic, P., Layman, M., Kraus, N., Flynn, J., Chalmers, J., \& Gesell, G. (1991). Perceived risk, stigma, and potential economic impacts of a high-level nuclear waste repository in Nevada. Risk Analysis, $11,683-696$.

Slovic, P. (1995). The construction of preference. American Psychologist, 50, 364-371.

Slovic, P. (1997). Trust, emotion, sex, politics, and science: Surveying the riskassessment battlefield. In M.H. Bazerman, D. M. Messick, A. E. Tenbrunsel, \& K. A. WadeBenzoni (Eds.), Environment, ethics, and behavior (pp. 277-313). San Francisco: New Lexington. 
Szalay, L. B., \& Deese, J. (1978). Subjective meaning and culture: An assessment through word associations. Hillsdale,NJ: Lawrence-Erlbaum.

Tversky, A. (1972). Elimination by aspects: A theory of choice. Psychological Review, 79, 281-299.

Tversky, A., \& Kahneman, D. (1974). Judgment under uncertainty: Heuristics and biases. Science, 185, 1124-1131.

Wilson, T. D., Lisle, D. J., Schooler, J. W., Hodges, S. D., Klaaren, K. J., \& LaFleur, S. J. (1993, June). Introspecting about reasons can reduce post-choice satisfaction. Personality and Social Psychology Bulletin, 19(3), 331-339.

Zajonc, R. B. (1980). Feeling and thinking: Preferences need no inferences. American Psychologist, 35. 151-175. 
Table 1. Images, Ratings, And Summation Scores For Respondent 132.

\begin{tabular}{|c|c|c|c|}
\hline Sample Subject & $\begin{array}{l}\text { Image } \\
\text { Number }\end{array}$ & & Image Rating \\
\hline SAN DIEGO & 1 & & 2 very nice \\
\hline SAN DIEGO & 2 & & 2 good beaches \\
\hline SAN DIEGO & 3 & & $2 z 00$ \\
\hline SAN DIEGO & 4 & & 1 busy freeway \\
\hline SAN DIEGO & 5 & & 1 easy to find way \\
\hline \multirow[t]{2}{*}{ SAN DIEGO } & 6 & & 2 pretty town \\
\hline & & Sum $=$ & 10 \\
\hline DENVER & 1 & & 2 high \\
\hline DENVER & 2 & & 0 crowded \\
\hline DENVER & 3 & & $2 \mathrm{cool}$ \\
\hline DENVER & 4 & & 1. pretty \\
\hline DENVER & 5 & & -2 busy airport \\
\hline \multirow[t]{2}{*}{ DENVER } & 6 & & -2 busy streets \\
\hline & & Sum $=$ & 1 \\
\hline LAS VEGAS & 1 & & -2 rowdy town \\
\hline LAS VEGAS & 2 & & -1 busy town \\
\hline LAS VEGAS & 3 & & -1 casinos \\
\hline LAS VEGAS & 4 & & -1 bright lights \\
\hline LAS VEGAS & 5 & & -2 too much gambling \\
\hline \multirow[t]{2}{*}{ LAS VEGAS } & 6 & & 0 out of the way \\
\hline & & Sum $=$ & -7 \\
\hline LOS ANGELES & 1 & & -2 smoggy \\
\hline LOS ANGELES & 2 & & -2 crowded \\
\hline LOS ANGELES & 3 & & -2 dirty \\
\hline LOS ANGELES & 4 & & -1 foggy \\
\hline LOS ANGELES & 5 & & 0 sunny \\
\hline \multirow[t]{2}{*}{ LOS ANGELES } & 6 & & -2 drug place \\
\hline & & Sum $=$ & -9 \\
\hline
\end{tabular}

Note. Based on these summation scores, this person's predicted preference order for a vacation site would be: San Diego, Denver, Las Vegas, and Los Angeles. Source: Slovic et al. (1991). 
Table 2. Scales for semantic differential ratings. Labels in parenthesis are scale descriptors used in subsequent analyses.

\begin{tabular}{llllllllll}
\hline Bad & 1 & 2 & 3 & 4 & 5 & 6 & 7 & Good & (BADGOOD) \\
Boring & 1 & 2 & 3 & 4 & 5 & 6 & 7 & Exciting & (EXCITING) \\
Worthless & 1 & 2 & 3 & 4 & 5 & 6 & 7 & Valuable & (VALUABLE) \\
Strong & 1 & 2 & 3 & 4 & 5 & 6 & 7 & Weak & (STRONG) \\
Passive & 1 & 2 & 3 & 4 & 5 & 6 & 7 & Active & (ACTIVE) \\
Not risky & 1 & 2 & 3 & 4 & 5 & 6 & 7 & Highly risky & (RISKY) \\
\hline
\end{tabular}


Table 3. Scales used to evaluate industry groups. Identifiers in bold italics correspond to variable names in the analysis of data.

How familiar are you with companies in this group? (FAML)

$\begin{array}{cccc}\text { Not } & \text { Slightly } & \text { Somewhat } & \text { Very } \\ \text { familiar } & \text { familiar } & \text { familiar } & \text { familiar } \\ 1 & 2 & 3 & 4\end{array}$

Does one or perhaps two significant company(ies) come to mind when you think of this industry group? (THINK CO.)

$$
\text { YES NO }
$$

Compared to the market average for all stocks traded on the New York Stock Exchange, how well do you think stocks in this industry group did last year (i.e., 1994)? (JUDGE 1994)

$\begin{array}{ccccc}\begin{array}{c}\text { Well below } \\ \text { market average }\end{array} & \begin{array}{c}\text { Below market } \\ \text { average }\end{array} & \begin{array}{c}\text { At market } \\ \text { average }\end{array} & \begin{array}{c}\text { Above market } \\ \text { average }\end{array} & \begin{array}{c}\text { Well above } \\ \text { market average }\end{array} \\ 1 & 2 & 3 & 4 & 5\end{array}$

Compared to the market average for stocks traded on the New York Stock Exchange, how well do you think stocks in this industry group will do this year? (JUDGE 1995)

$\begin{array}{ccccc}\begin{array}{c}\text { Well below } \\ \text { market average }\end{array} & \begin{array}{c}\text { Below market } \\ \text { average }\end{array} & \begin{array}{c}\text { At market } \\ \text { average }\end{array} & \begin{array}{c}\text { Above market } \\ \text { average }\end{array} & \begin{array}{c}\text { Well above } \\ \text { market average }\end{array} \\ 1 & 2 & 3 & 4 & 5\end{array}$

If you were considering buying stocks in new companies, how likely would you be to buy shares of a new company that belonged to this industry group? (BUY IPO)

$\begin{array}{cccc}\begin{array}{c}\text { Very } \\ \text { unlikely }\end{array} & \begin{array}{c}\text { Somewhat } \\ \text { unlikely }\end{array} & \begin{array}{c}\text { Somewhat } \\ \text { likely }\end{array} & \begin{array}{c}\text { Very } \\ \text { likely }\end{array} \\ 1 & 2 & 3 & 4\end{array}$


Table 4. Intercorrelations between three judgmental and three actual measures of financial performance.

\begin{tabular}{lccccc}
\hline & Judge 1995 & BUY IPO & $\begin{array}{c}\text { Simple } \\
\text { average }\end{array}$ & $\begin{array}{c}\text { Weighted } \\
\text { average }\end{array}$ & $\begin{array}{c}\text { Median } \\
\text { return }\end{array}$ \\
\hline Judge 1994 & .83 & .79 & .21 & .38 & .08 \\
Judge 1995 & -- & .90 & .14 & .36 & -.03 \\
BUY IPO & &.--10 & .10 & .23 & -.09 \\
\hline
\end{tabular}


Table 5. Intercorrelation coefficients for six semantic differential scales."

\begin{tabular}{lccccccc}
\hline & EXCITING & VALUABLE & STRONG & ACTIVE & RISKY & Imagery & Think Co. \\
\hline BADGOOD & .52 & .78 & -.63 & .28 & -.23 & .83 & $\ldots .20$ \\
EXCITING & - & .33 & -.51 & .77 & .36 & .43 & -.33 \\
VALUABLE & & - & -.62 & .32 & .02 & .50 & .04 \\
STRONG & & & - & -.67 & .02 & -.49 & .38 \\
ACTIVE & & & & - & .45 & .15 & -.33 \\
RISKY & & & & & - & -.30 & .04 \\
Imagery & & & & & & & -.28 \\
\hline
\end{tabular}

$\mathrm{a}_{\mathrm{r}}>.26$ is significant at $\mathrm{p}<.05 ; \underline{\mathrm{r}}>.34$ is significant at $\mathrm{p}<.01$. 
Table 6. Summary of stepwise regression analyses predicting judged financial performance from affect and imagery measures, with image ratings forced into the regression first. Table entries are partial correlations $\left(\mathrm{p}<.05\right.$ ), followed by the multiple $\mathrm{R}^{2}$ value for each judgmental variable.

\begin{tabular}{lccc} 
& Judge 1994 & Judge 1995 & BUY IPO \\
\hline IMAGE (forced) & .44 & .49 & .56 \\
STRONG & .60 & .71 & .64 \\
BADGOOD & .21 & & \\
VALUABLE & .27 & & \\
FAMIL & & .18 & .28 \\
Overall R & .68 & .78 & .80 \\
\hline
\end{tabular}


Table 7. Percentages of Associations in Each Superordinate Category

\begin{tabular}{lrcrccccc}
\hline \multicolumn{1}{c}{ Behavior } & $\begin{array}{c}\text { Positive } \\
\text { concepts }\end{array}$ & $\begin{array}{c}\text { Positive } \\
\text { outcomes }\end{array}$ & $\begin{array}{c}\text { Negative } \\
\text { concepts }\end{array}$ & $\begin{array}{c}\text { Negative } \\
\text { outcomes }\end{array}$ & $\begin{array}{c}\text { Miscella- } \\
\text { neous }\end{array}$ & $\begin{array}{c}\text { Uncate- } \\
\text { gorized }\end{array}$ \\
\hline Beer & 4.3 & 25.9 & 21.3 & 24.0 & 13.9 & 10.7 & 1,895 \\
Liquor & 4.5 & 17.5 & 23.3 & 28.6 & 15.1 & 11.0 & 1,820 \\
Cigarettes & 1.6 & 5.6 & 30.6 & 41.5 & 12.8 & 7.9 & 1,822 \\
Marijuana & 2.9 & 11.2 & 33.7 & 29.2 & 14.6 & 8.5 & 1,708 \\
Sexual intercourse & 10.5 & 36.0 & 8.2 & 10.6 & 19.7 & 15.0 & 1,741 \\
Condom use & 40.5 & 14.7 & 13.6 & 14.0 & 4.7 & 12.4 & 1,562 \\
Exercise & 7.9 & 45.6 & 7.5 & 7.3 & 22.8 & 8.8 & 1,868 \\
Seat belt & 17.8 & 34.5 & 29.6 & 3.8 & 6.1 & 8.1 & 1,663 \\
\hline
\end{tabular}


Table 8. Image Category Structure for Drinking Beer and Having Sexual Intercourse

\begin{tabular}{|c|c|c|}
\hline & Drinking beer & Having sexual intercourse \\
\hline $\begin{array}{l}\text { 1. Positive } \\
\text { concepts }\end{array}$ & $\begin{array}{l}\text { 1a. Good taste } \\
\text { 1b. Cold/refreshing } \\
\text { 1c. Socially accepted } \\
\text { 1d. Other }\end{array}$ & $\begin{array}{l}\text { la. Awesome/good } \\
\text { 1b. Erotic/sexy } \\
\text { 1c. Special }\end{array}$ \\
\hline $\begin{array}{l}\text { 2. Negative } \\
\text { concepts }\end{array}$ & $\begin{array}{l}\text { 2a. Bad taste } \\
\text { 2b. Bad smell } \\
\text { 2c. Expensive } \\
\text { 2d. Illegal } \\
\text { 2e. Dangerous/scary } \\
\text { 2f. Other }\end{array}$ & $\begin{array}{l}\text { 2a. Dangerous/scary } \\
\text { 2b. Other }\end{array}$ \\
\hline $\begin{array}{l}\text { 3. Positive } \\
\text { outcomes }\end{array}$ & $\begin{array}{l}\text { 3a. Fun/pleasure } \\
\text { 3b. Positive affective change } \\
\text { 3c. Relaxation } \\
\text { 3d. Arousal/sensation seeking } \\
\text { 3e. Sexual facilitation } \\
\text { 3f. Social facilitation }\end{array}$ & $\begin{array}{l}\text { 3a. Fun/enjoyment } \\
\text { 3b. Intimacy/affiliation } \\
\text { 3c. Love/romance } \\
\text { 3d. Arousal } \\
\text { 3e. Gratification/orgasm } \\
\text { 3f. Positive affective change } \\
\text { 3g. Relaxation } \\
\text { 3h. Social facilitation }\end{array}$ \\
\hline $\begin{array}{l}\text { 4. Negative } \\
\text { outcomes }\end{array}$ & $\begin{array}{l}\text { 4a. Negative affective change } \\
\text { 4b. Cognitive impaiment } \\
\text { 4c. Social impairment } \\
\text { 4d. Bad breath } \\
\text { 4e. Weight gain } \\
\text { 4f. Violence/crime } \\
\text { 4g. Hangover } \\
\text { 4h. Health damage } \\
\text { 4i. Accidents } \\
\text { 4j. Punishment } \\
\text { 4k. Emotional disinhibition } \\
\text { 4l. Addiction } \\
\text { 4m. Death } \\
\text { 4n. Other }\end{array}$ & $\begin{array}{l}\text { 4a. Social stigma/impaiment } \\
\text { 4b. Negative affective change } \\
\text { 4c. Pain } \\
\text { 4d. Abortion } \\
\text { 4e. AIDS/STDs/disease } \\
\text { 4f. Punishment } \\
\text { 4g. Other }\end{array}$ \\
\hline
\end{tabular}


Table 9. Standardized Regression Coefficients for Predicting Participation in Health-Related Behaviors

\begin{tabular}{lccc}
\hline & \multicolumn{3}{c}{ Predictor variables } \\
\cline { 2 - 3 } Behavior & Positive image score & Negative image score & $\mathrm{R}^{2}$ \\
\hline Beer & $.32^{* *}$ & $.27^{* *}$ & .29 \\
Liquor & $.46^{* *}$ & $.13^{*}$ & .31 \\
Cigarettes & - & $.41^{* *}$ & .14 \\
Marijuana & $.40^{* *}$ & $.18^{* *}$ & .29 \\
Sexual intercourse & $.38^{* *}$ & - & .14 \\
Condom use & .19 & .19 & .11 \\
Exercise & $.36^{* *}$ & $.17^{* *}$ & .23 \\
Seat-belt use & - & $.20^{* *}$ & .05 \\
\hline
\end{tabular}

$$
\begin{array}{rl}
* & \mathrm{p}<.05 \\
* * \mathrm{p} & <.01
\end{array}
$$

${ }^{a}$ Because the negative ratings by definition carried a negative sign, higher scores reflected less negative (i.e., more positive) ratings. Therefore, the regression coefficients would be expected to have a positive sign when predicting participation. This in fact occurred, as is shown in this column of the table. 
Table 10. Association Between Predicted and Self-Reported Participation in Three HealthThreatening Behaviors

\begin{tabular}{lccccccc} 
Self-report & \multicolumn{2}{c}{$\begin{array}{c}\text { Drinking beer } \\
\text { Prediction }\end{array}$} & No & Yes & \multicolumn{2}{c}{$\begin{array}{c}\text { Sexual intercourse } \\
\text { Prediction }\end{array}$} & \multicolumn{2}{c}{$\begin{array}{c}\text { Condom use } \\
\text { Prediction }\end{array}$} \\
\hline Never & 108 & 11 & 166 & Yes & No & Yes \\
Occasionally & 110 & 73 & 61 & 30 & 56 & 17 \\
Frequently & 17 & 80 & 58 & 42 & 10 & 23 \\
\hline
\end{tabular}

Note. Frequencies of behaviors do not match frequencies in Table 6 because persons with missing data were deleted from the regression analysis.

${ }^{a}$ Prediction equation included average image rating and age: $\mathrm{R}^{2}=.31$

${ }^{b}$ Prediction equation included average image rating, gender, and age: $\mathrm{R}^{2}=.20$

${ }^{c}$ Prediction equation included average image rating and gender: $\underline{R}^{2}=.16$

${ }^{d}$ Includes only those who had sexual intercourse during 6 months prior to survey. 


\section{Figure Captions}

Figure 1. Probability of vacationing in a particular city as a function of image scores. Upper row of numbers indicates the number of people with that image score who vacationed in the city; lower row is the number who did not vacation in the city; * marks the proportion who vacationed. The curve is the best-fit logistic function to these probabilities.

Figure 2. Probability of vacationing in a particular state as a function of image scores. Upper row of numbers indicates the number of people with that image score who vacationed in the state; lower row is the number who did not vacation in the state; $\mathbf{X}$ marks the proportion who vacationed. The curve is the best-fit logistic function to these probabilities.

Figure 3. Probability of vacationing in a particular city after June, 1988, as a function of image scores elicited prior to that date (Phoenix survey). Upper row of numbers indicates the number of people with that image score who vacationed in the city; lower row is the number who did not vacation in the city; ${ }^{*}$ marks the proportion who vacationed. The curve is the best-fit logistic function to these proportions. Source: Slovic et al. (1991).

Figure 4. Probability of vacationing in a particular state after June, 1988 as a function of image scores clicited prior to that date (Phoenix survey). Upper row of numbers indicates the number of people with that image score who vacationed in the state; lower row is the number who did not vacation in the state; * marks the proportion who vacationed. The curve is the bestfit logistic function to these proportions. Source: Slovic et al. (1991).

Figure 5. Percentages for each superordinate image category by participation (never vs. frequent) during the 6 months prior to the survey. 


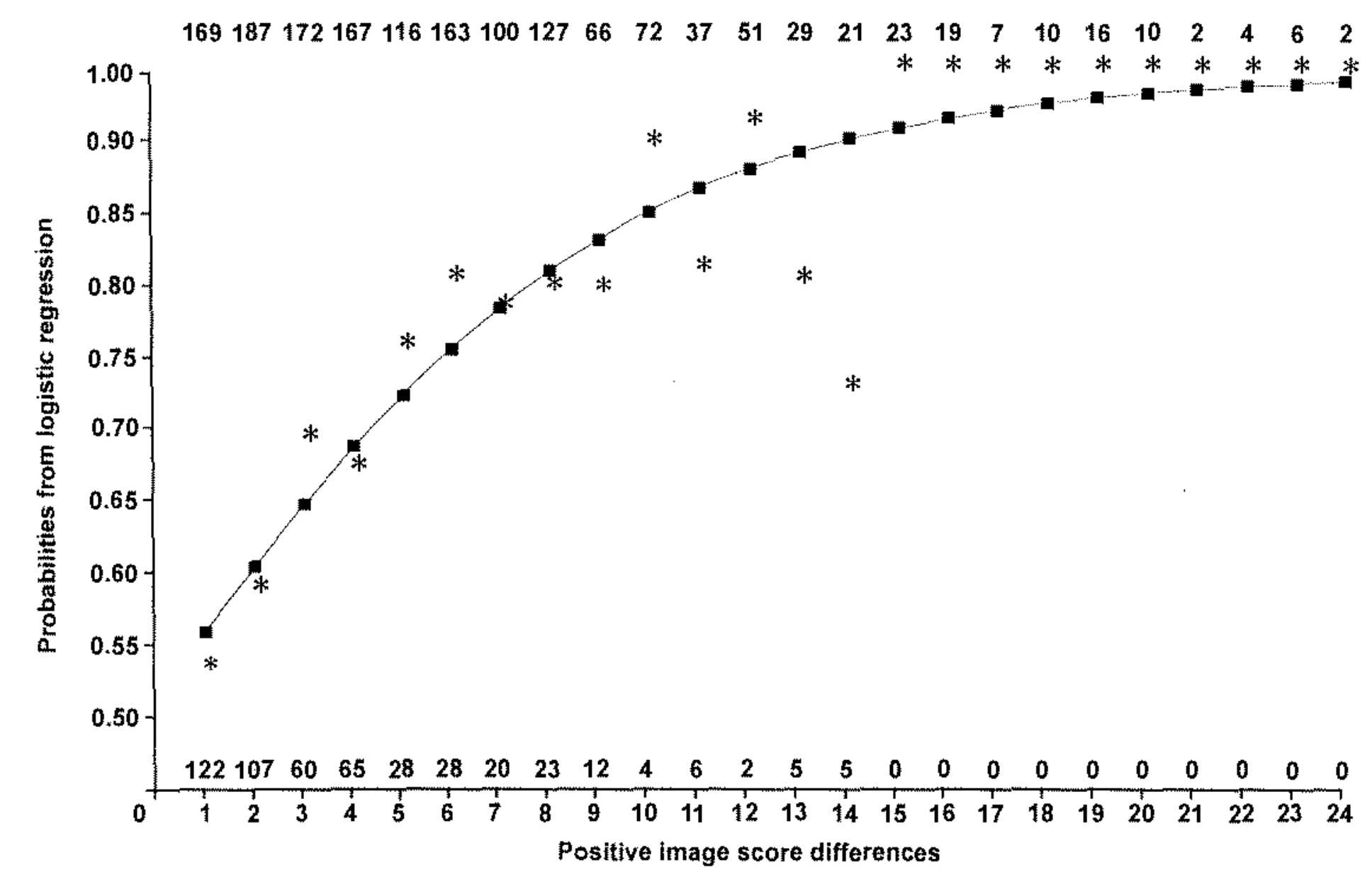

Figure 1. Probability of vacationing in a particular city as a function of image scores. Upper rows of numbers indicates the number of people who vacationed in the city; lower row is the number who did not vacation in the city; * marks the proportion who vacationed. The curve is the best-fit logistic function to these probabitities. 


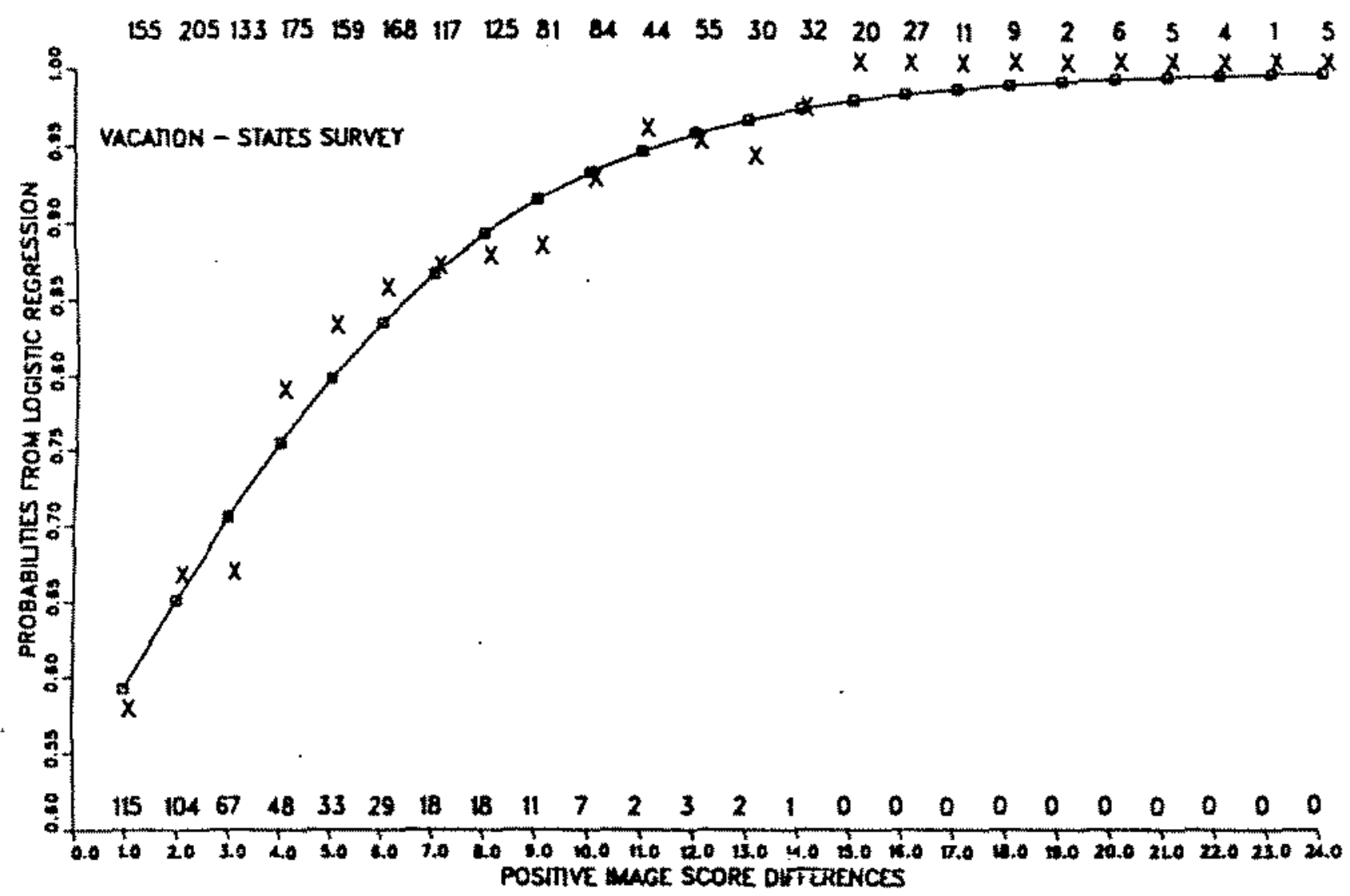

Figure 2. Probability of vacationing in a particular state as a function of image scores. Upper row of numbers indicates the number of people with that image score who vacationed in the state; lower row is the number who did not vacation in the state: $\mathbf{X}$ marks the proportion who vacationed. The curve is the best-fit logistic function to these probabilities. 


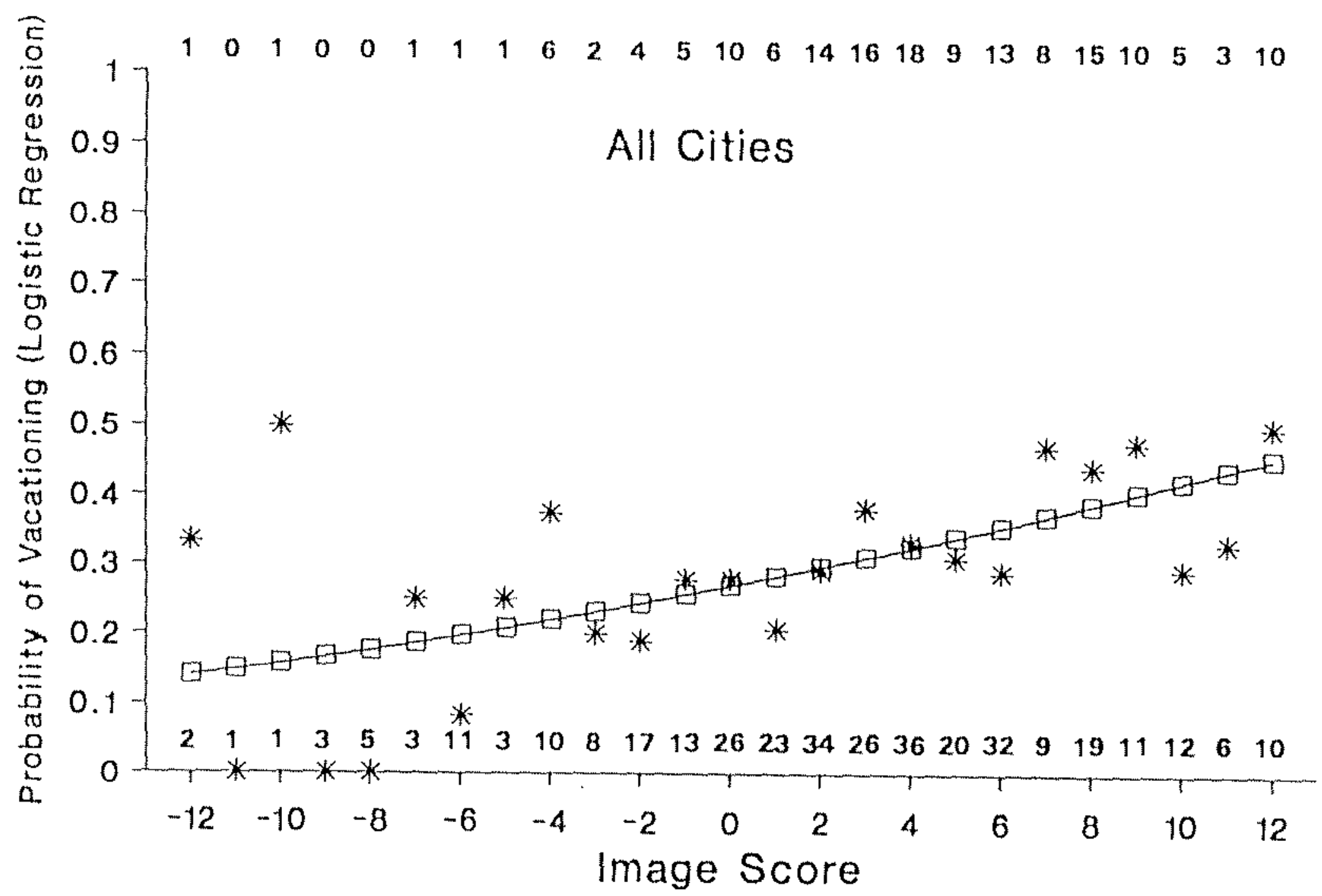

Figure 3. 


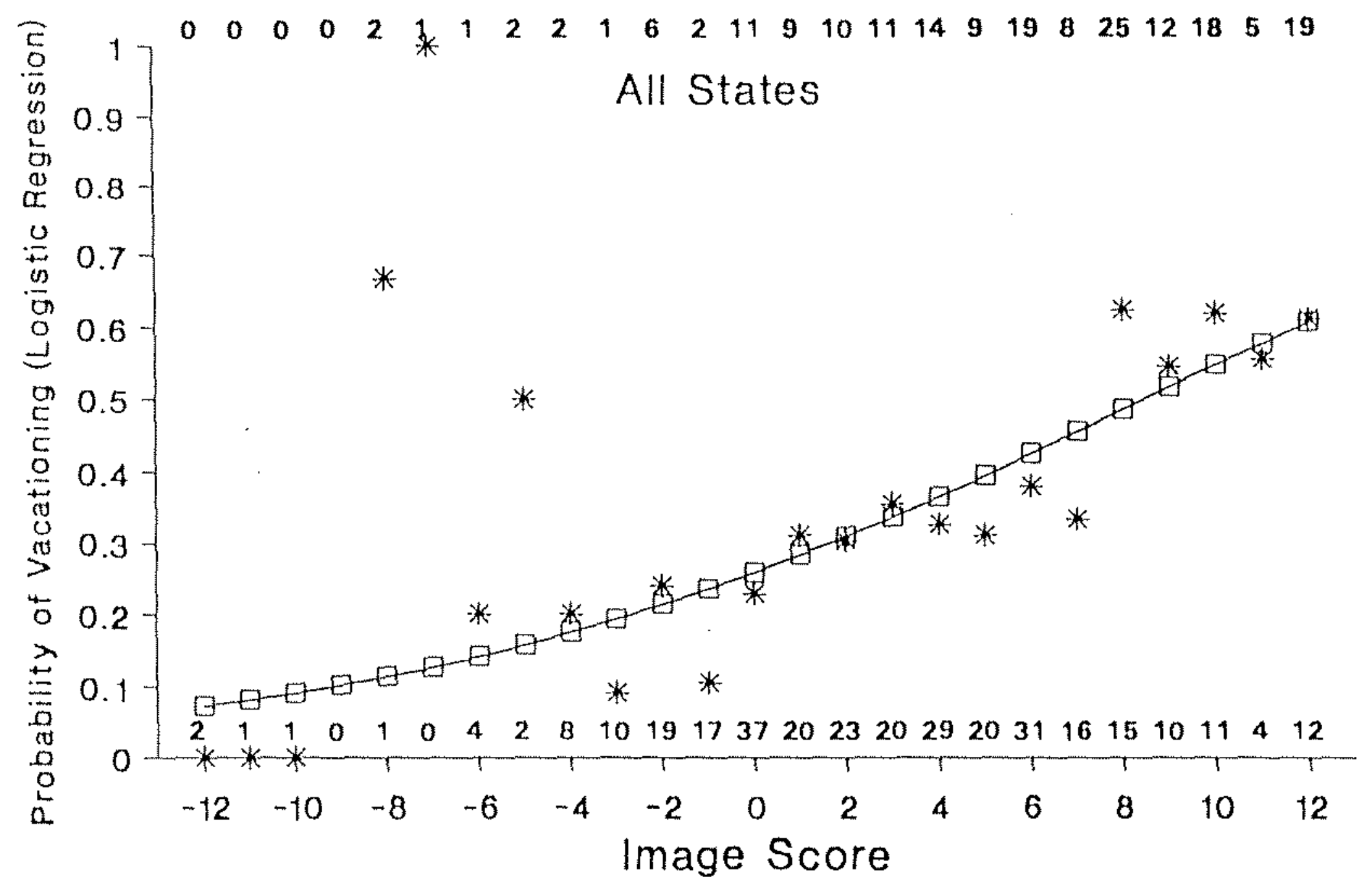

Figure 4 


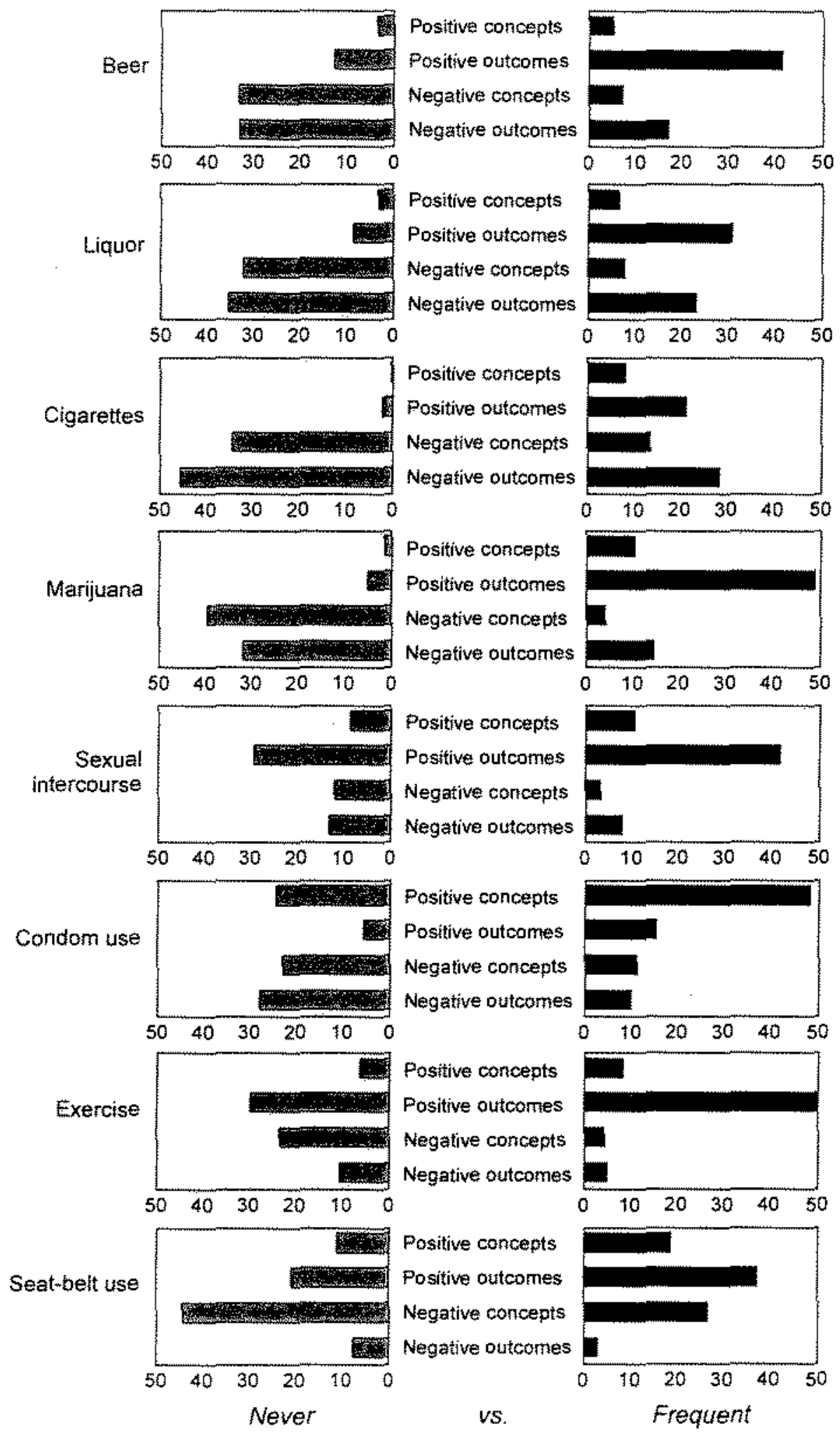

Figure 5. Percentages for each superordinate image category by participation (never versus frequent) during the 6 months prior to the survey. 